\title{
Properties of Jet-Plated Ni Coating on Ti Alloy (Ti6A14V) with Laser Cleaning Pretreatment
}

\author{
Xiao Wang ${ }^{1,+}{ }^{,}$Mingyang $X u^{1,+}$, Zhanwen Wang ${ }^{1}$, Lida Shen ${ }^{1, * \mathbb{C}}$, Mingbo Qiu ${ }^{1}$, \\ Zongjun Tian ${ }^{1}$, Muhammad Naveed Ahsan ${ }^{2}$ and Changjiang Wang ${ }^{3}(\mathbb{D}$ \\ 1 National Key Laboratory of Science and Technology on Helicopter Transmission, \\ Nanjing University of Aeronautics and Astronautics, Nanjing 210016, China; wangx@jitri.org (X.W.); \\ myxu1994@126.com (M.X.); zwwang0506@163.com (Z.W.); qiumingbo@nuaa.edu.cn (M.Q.); \\ tianzj@nuaa.edu.cn (Z.T.) \\ 2 Center of Excellence in Science and Applied Technologies, Sector H-11, Islamabad 44000, Pakistan; \\ naveedahsan.ch@gmail.com \\ 3 Department of Engineering and Design, University of Sussex, Sussex House, Brighton BN1 9RH, UK; \\ C.J.Wang@sussex.ac.uk \\ * Correspondence: ldshen@nuaa.edu.cn; Tel.: +86-025-8489-2520 \\ + These authors contributed equally to this work.
}

Received: 4 January 2019; Accepted: 3 February 2019; Published: 20 February 2019

check for updates

\begin{abstract}
The surface mechanical properties of the Selective Laser Melting (SLM) formed Ti6Al4V samples were improved by adopting a novel laser cleaning pretreatment process combined with a jet electrodeposition process. This paper aimed to investigate the effects of different laser powers on the morphologies and adhesions of the nickel coatings. The advantages of the laser cleaning process are no grinding, no contact, high efficiency and environmental protection. The morphologies, adhesion, wear resistance, and hardness of the coatings were characterized. The results indicate that when the laser energy density reached $20 \%\left(4 \mathrm{~J} / \mathrm{cm}^{2}\right)$, the contaminations on the substrate and the oxide layer were removed and the crystalline grain of the coating was $15.3 \mathrm{~nm}$. The shallow pits generated by laser burning increased the adhesion of the coatings. In addition, when the laser energy density increased to $6 \mathrm{~J} / \mathrm{cm}^{2}$, a yellow oxide layer was produced on the surface of the cleaned titanium alloy. Moreover, the wear resistance of the titanium alloy after the nickel plating was improved. The wear volume was only $0.046 \mathrm{~mm}^{3}$, and the hardness increased to $1967.6 \mathrm{~N} / \mathrm{mm}^{2}$.
\end{abstract}

Keywords: laser cleaning; titanium alloy; jet electrodeposition; friction properties

\section{Introduction}

As a structural material, titanium alloy has a high specific strength, low density, and good corrosion resistance. Titanium alloy is one of the main materials used in the defense field such as aerospace and weapons [1]. Selective laser melting (SLM) is a type of metal additive manufacturing method that produces molded parts with a high dimensional accuracy, high density and low manufacturing cost, making it ideal when forming some titanium alloy parts [2]. The titanium alloy parts prepared by SLM unfortunately have a low hardness, easy wear, and are very sensitive to adhesive and fretting wear, thus limiting their popularization and application [3]. Improving the surface properties of SLM formed parts is important for their stability and safety during actual use.

Methods for improving the surface properties of titanium alloys include electroless plating [4,5], electrodeposition [6], laser cladding [7,8], spray coating [9], air atmosphere treatment [10], laser assisted machining [11,12] and laser heat treatment [13-15]. Electrodeposition with a simple process and low cost is commonly used in the preparation of nan materials, composite plating, and special 
function plating $[15,16]$. As a novel type of electrodeposition technology, jet electrodeposition has an excellent liquid phase mass transfer effect, high current density during processing, and achieves deposition speeds several times higher than traditional electrodeposition [17-19]. Wang et al. [20] used a rotating device at the cathode to prepare $\mathrm{Ni}-\mathrm{CeO}_{2}$ composite coating via jet electrodeposition. Ma et al. [21] successfully prepared Ni-AlN nano-coating via jet pulse electrodeposition and ultrasonic wave. Determining an appropriate electrodeposition process that provides new physical characteristics to the titanium alloy will improve its surface properties. As an important method to improve the surface of metals, the application of electroplated nickel in titanium alloys can improve the hardness and wear resistance of the surface. There are some reports of nickel plating in titanium alloys, but most of the coating adhesion is not adequate, and subsequent heat treatment processes are often required to further enhance the adhesion of the coating [22]. The surface of the titanium alloy easily oxidizes in the air to form a dense oxide film, making it difficult for the coating to adhere tightly. The deposition pretreatment is a key factor affecting both the coating performance and adhesion.

Traditional pretreatments include sanding, polishing, degreasing, and pickling activation, which are time consuming and cumbersome [23]. Laser cleaning is a 'green' cleaning method that eliminates the need for chemical reagents and cleaning fluids, which eliminate the environmental pollution problems caused by chemical cleaning $[24,25]$. The non-contact of laser cleaning avoids generating mechanical forces and secondary contamination of the abrasive media. In this paper, the novel laser cleaning pretreatment process was used to study the effects that different laser cleaning powers had on the morphology and the bonding force of the coating.

\section{Experimental System}

\subsection{Experimental Mechanism and Device}

Figure 1 shows the experimental process that used laser cleaning for the contaminants and oxide layers on the titanium alloy. During the cleaning process, the laser was irradiated on the surface of the material, the substrate, contaminants, and oxide layers, which underwent thermal expansion. As the laser irradiation time increased, the difference between the thermal expansion coefficient of the contaminants and oxide layer, and the substrate, caused pressure at the interface. The contaminants and oxide layers buckled, vibrated, and were peeled off from the substrate [26]. The cleaned substrate was immediately placed on the jet electrodeposited cathode stage for deposition processing. Under the high current density, the nickel ions sprayed in the electrolyte on the substrate rapidly reduced to form a nickel plating layer, which prevented the substrate from coming in contact with the oxygen in the air. As the deposition time increased, a dense nickel coating with a certain thickness adhered to the substrate to provide protection.

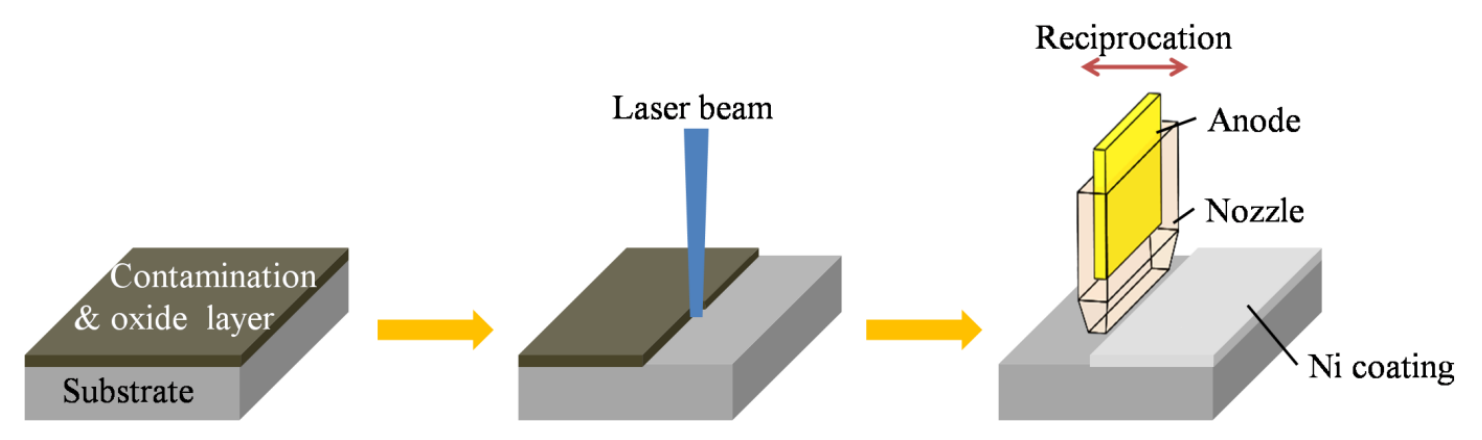

Figure 1. Experimental process.

The experimental apparatus includes a laser and a jet electrodeposition. The pulsed fiber laser consisted of the ZB-LM-20P laser system from the Nanjing Advanced Laser Technology Research Institute. The specific parameters are shown in Table 1. Laser energy density is the main parameter 
that determines the thermal effect of the laser. The percentage of energy density indicates the amount of energy. For example, a $10 \%$ laser energy density is actually $2 \mathrm{~J} / \mathrm{cm}^{2}$.

Table 1. Laser system parameters.

\begin{tabular}{cc}
\hline Parameter & Value \\
\hline Wave length $(\mathrm{nm})$ & 1064 \\
Pulse width $(\mathrm{ns})$ & 100 \\
Spot diameter $(\mu \mathrm{m})$ & 35 \\
Output power $(\mathrm{W})$ & 30 \\
Energy density $\left(\mathrm{J} / \mathrm{cm}^{2}\right)$ & 20 \\
Frequency $(\mathrm{KHz})$ & 20 \\
Scanning line speed $(\mathrm{mm} / \mathrm{s})$ & 500 \\
\hline
\end{tabular}

The jet electrodeposition apparatus is shown in Figure 2. The electrolyte was drawn from the plating bath by the pump, passed through the flow meter and the anode chamber, and finally ejected onto the cathode stage by the nozzle. Nickel beads were placed in the anode chamber to maintain the $\mathrm{Ni}^{2+}$ content in the system. The substrate was fixed on the cathode stage, and the Z-axis that was connected to the anode chamber controlled the distance between the nozzle and the cathode stage. The $X$-axis reciprocated left and right for the automatic deposition processing.

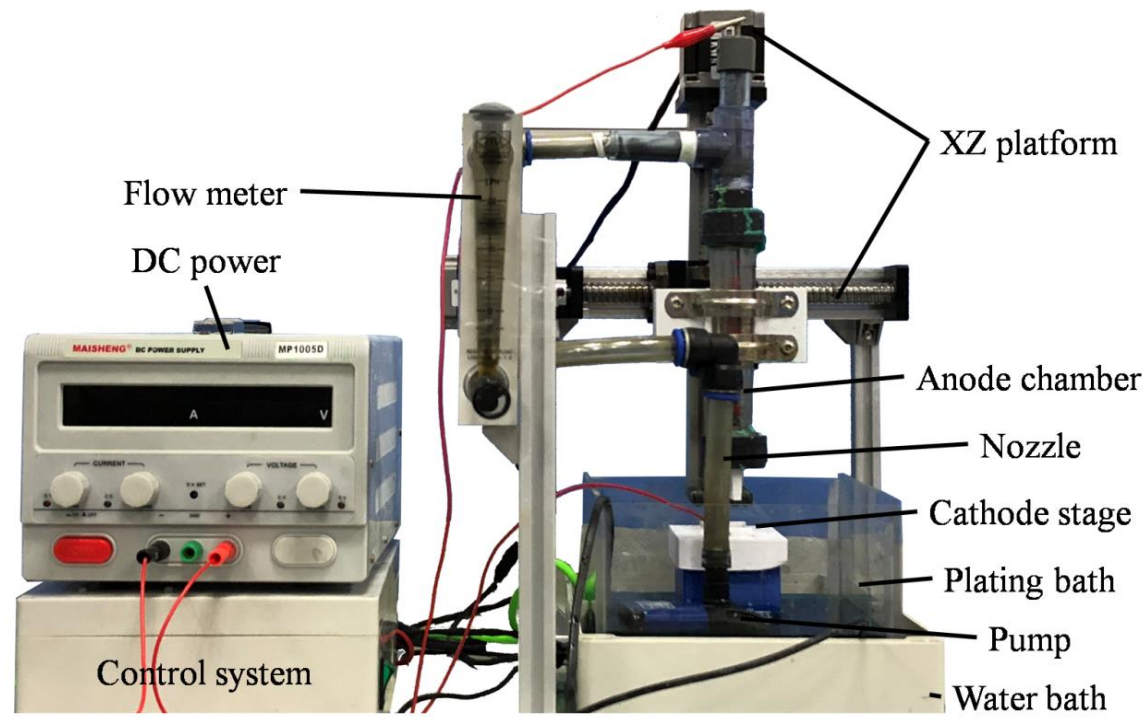

Figure 2. The jet electrodeposition device.

\subsection{Experimental Conditions}

The substrate was a $20 \mathrm{~mm} \times 20 \mathrm{~mm} \times 3 \mathrm{~mm}$ Ti6Al4V titanium alloy printed on a self-developed SLM machine. Before the experiment, the substrate used the traditional pretreatment method of grinding, polishing, degreasing and pickling activation. The substrates were pretreated with different power lasers immediately after the preparation. The composition of the electrolyte is shown in Table 2. The experimental reagents were analytical grade, and the solutions were prepared using distilled water. $\mathrm{NiSO}_{4}$ was the main source of $\mathrm{Ni}^{2+}$ in the solution. $\mathrm{NiCl}_{2}$ performed as an anode activator to prevent anode passivation. $\mathrm{H}_{3} \mathrm{BO}_{4}$ was used as a buffering reagent to maintain the $\mathrm{pH}$ of the electrolyte. Saccharin was added as a brightener to reduce stress and to refine the grain size. 
Table 2. Bath compositions and operating conditions for the jet electrodeposition.

\begin{tabular}{cc}
\hline Bath Compositions and Operating Conditions & Content \\
\hline $\mathrm{NiSO}_{4} \cdot 6 \mathrm{H}_{2} \mathrm{O}(\mathrm{g} / \mathrm{L})$ & 260 \\
$\mathrm{NiCl}_{2} \cdot 6 \mathrm{H}_{2} \mathrm{O}(\mathrm{g} / \mathrm{L})$ & 40 \\
$\mathrm{H}_{3} \mathrm{BO}_{4}(\mathrm{~g} / \mathrm{L})$ & 40 \\
$\mathrm{C}_{7} \mathrm{H}_{5} \mathrm{O}_{3} \mathrm{NS}(\mathrm{g} / \mathrm{L})$ & 5 \\
Temperature $\left({ }^{\circ} \mathrm{C}\right)$ & 50 \\
$\mathrm{pH}$ & 4.0 \\
Current density $\left(\mathrm{A} / \mathrm{dm}^{2}\right)$ & 100 \\
Scanning speed $(\mathrm{mm} / \mathrm{s})$ & 4 \\
Plating Time $(\mathrm{min})$ & 30 \\
\hline
\end{tabular}

\subsection{Characterization Techniques and Methods}

The pretreated substrate was observed using an optical microscope (GX41; Olympus Co., Tokyo, Japan). A scanning electron microscope (S-4800; Hitachi Instruments Inc., Tokyo, Japan) was used to observe the surface topographies of the coatings. The coatings were analyzed using an $\mathrm{X}$-ray diffraction (XRD) spectrometer (DMAX-2500PC; Rigaku Corp., Tokyo, Japan) operated at $40 \mathrm{kV}$ and $150 \mathrm{~mA}$ with $\mathrm{Cu}-\mathrm{K} \alpha$ radiation $(\lambda=1.5406 \AA)$. A scratch test was performed on the instrument coating adhesion (WS-2005; Zhongke Kaihua Instruments Co., Lanzhou, China), and the coating adhesion was tested via the progressive loading method. The load was $40 \mathrm{~N}$, the length of the scratches was $3 \mathrm{~mm}$, the loading rate was $4 \mathrm{~mm} / \mathrm{min}$, and the static pressure time was $30 \mathrm{~s}$. A hardness tester (HV-1000; Shanghai Haowei Optoelectronic Technology Co., Ltd., Shanghai, China) was used to randomly select five points on the coatings for testing at $200 \mathrm{~g}$ loads and to average the values. The frictional properties of the coatings were tested on a friction and wear tester (SFT-2M; Zhongke Kaihua Instruments Co., Lanzhou, China). The counterpart was a $3 \mathrm{~mm}$ GCr15 steel ball with a $20 \mathrm{~N}$ load, $2 \mathrm{~mm}$ sliding radius, $300 \mathrm{r} / \mathrm{min}$ rotation speed, and 4 min test time.

\section{Results and Discussion}

\subsection{Surface Morphology}

Figure 3 shows the microscopic morphologies of the Ti6Al4V substrates (the optical microscope) and nickel coatings (the scanning electron microscope) after different pretreatments. The traditional pretreated substrate had significant scratches, and the coating had large grain size and a large number of nodular structures (Figure $3 a, a^{\prime}$ ). In Figure $3 b$, the substrate treated with a $10 \%$ laser energy density has no obvious laser spots. The grains of coating had a certain refinement, but did not prevent the formation of nodular structures (Figure $3 b^{\prime}$ ). Figure $3 c$ shows that the $20 \%$ laser-cleaned substrate had distinct strip laser spots. The grains were further reduced, but the surface of the coating was undulating, which was related to the surface topography of the substrate, because electrodeposition had the characteristic of replicating the surface topography of the substrate (Figure 3c'). The laser energy density increased to $30 \%$, which caused serious damage to the substrate while removing the contaminants and the oxide layers [27]. A large number of array laser spots with a certain depth appeared on the surface of the treated substrate (Figure 3d). During the deposition process, the metal reduction was more likely to occur at the nodular, due to the tip effect. $\mathrm{The}^{\mathrm{Ni}}{ }^{2+}$ at the pits were more difficult to reduce, resulting in a thicker coating at the protrusions and a thinner coating at the pits. The internal stress when the thickness of the plating layer was uneven impaired the structure and the coating adhesion, and at the same time enlarged the roughness of the coating [28]. Figure $3 \mathrm{~d}^{\prime}$ shows that the fine crystal grains were not observed and that the large crystal grains increased remarkably, while the quality of the coating decreased. 

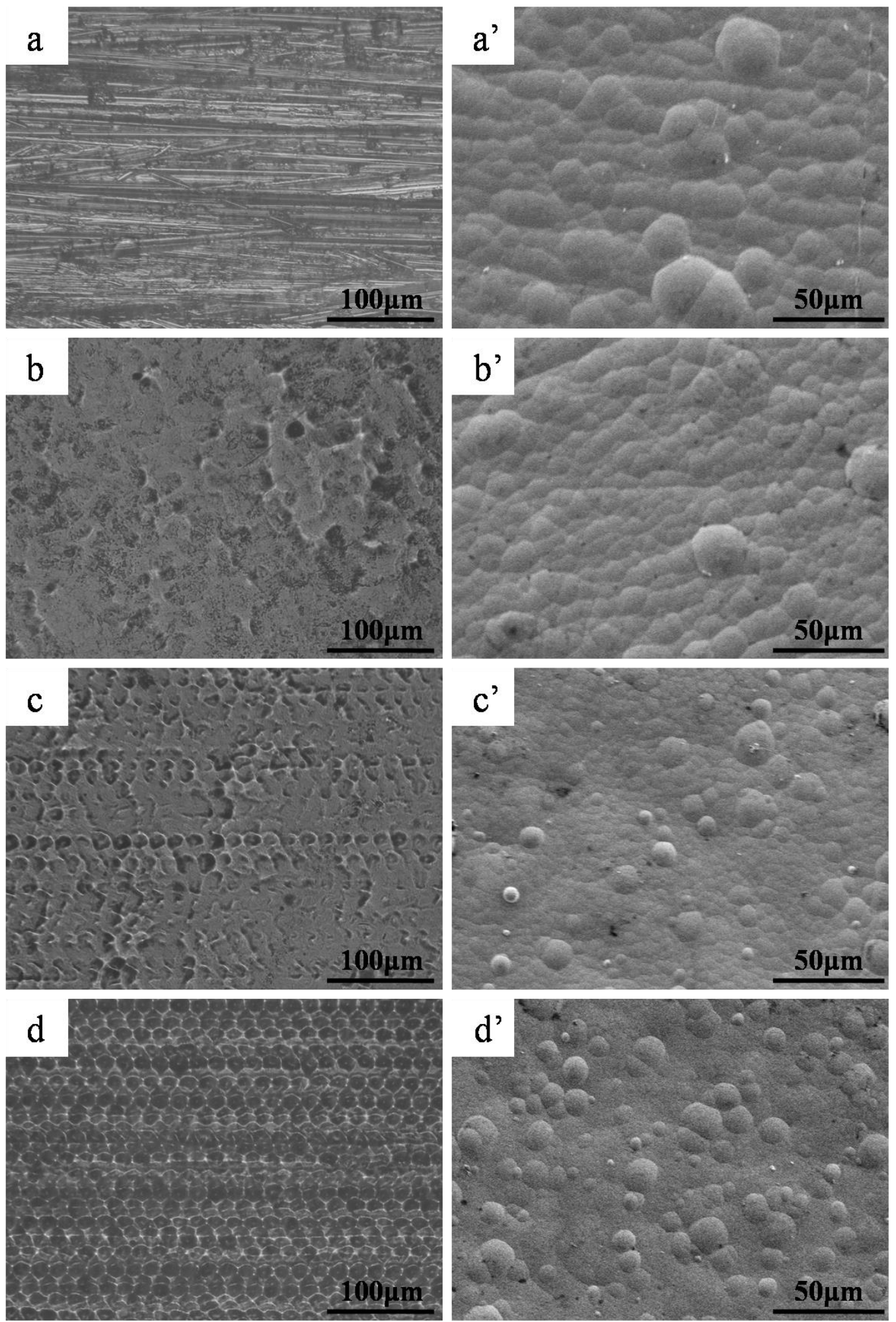

Figure 3. Surface morphologies of the substrates (left) and coatings (right): (a,a') traditional pretreatment; $\left(\mathbf{b}, \mathbf{b}^{\prime}\right)$ 10\% laser energy density cleaning; (c, $\left.\mathbf{c}^{\prime}\right)$ 20\% laser energy density cleaning; (d,d') 30\% laser energy density cleaning.

\subsection{XRD Analysis}

In order to further analyze the crystalline grain size and chemical composition of the coatings, we performed an X-Ray diffraction test. As shown in Figure 4, The crystallographic planes corresponding 
to the diffraction peaks of the traditional pretreatment and $20 \%$ laser energy density cleaning were (111), (200), (220), and (311). The structure was a face-centered cubic structure, and the preferred orientation for growth was (111), from which one can consider that the different pretreatment methods did not change the preferred orientation. The crystalline grain size of the traditional pretreatment coating was calculated by the Debye-Scherrer formula to be $28.5 \mathrm{~nm}$, and the crystalline grain size of the coating from the $20 \%$ laser energy density cleaning was $15.3 \mathrm{~nm}$. The slightly rough coating surface after the $20 \%$ laser energy density cleaning enhanced the tip effect relative to a flat surface. Therefore, the current density was larger at the tip, producing a nickel coating with a smaller grain size [28]. When the laser energy density reached 30\%, the cleaned surface was too rough, which broke the balance between the tip effect and the mass transfer of the solution, and caused the crystal grains to increase.

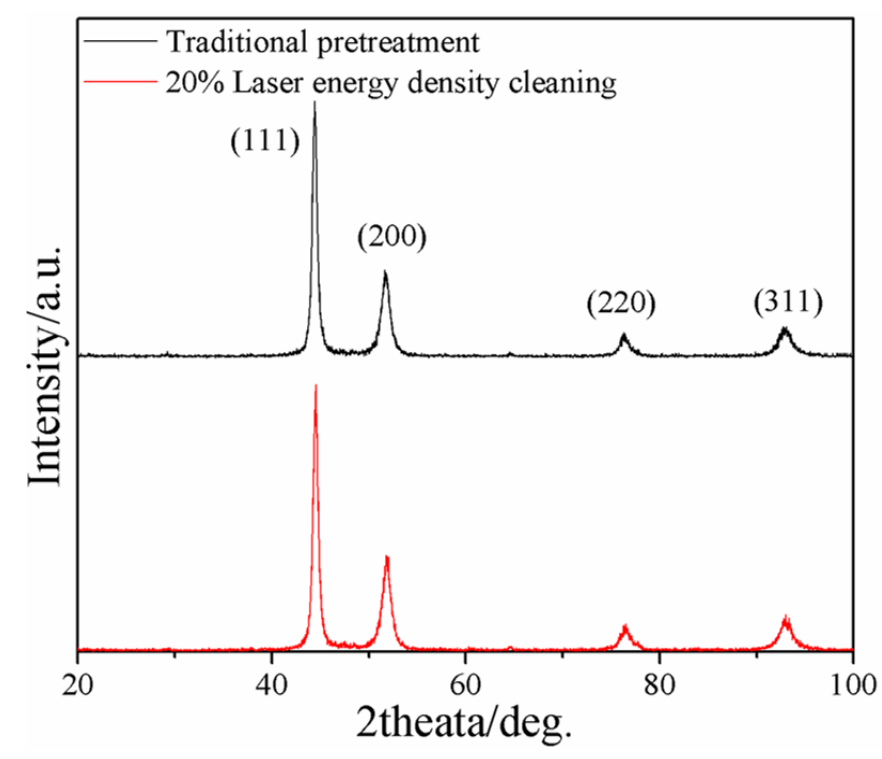

Figure 4. XRD patterns of the coatings.

\subsection{Coating Adhesion}

The adhesion test was performed on the coating under the conditions of a load of $40 \mathrm{~N}$ and a scratch length of $3 \mathrm{~mm}$. Figure 5 shows the effect of different pretreatments on the adhesion of the coatings. When the curve shows a significant fluctuation, the critical load at this time is the adhesion force of the coating. The coating adhesion of the traditional pretreatment was $17.8 \mathrm{~N}$, while the $20 \%$ laser energy density cleaning had a coating adhesion of up to $30.7 \mathrm{~N}$. As the laser power increased, the adhesion initially increased and then decreased. The adhesion at $10 \%$ laser energy density was only $9.5 \mathrm{~N}$. When the energy density reached 30\%, the adhesion of the coating decreased from $30.7 \mathrm{~N}$ to $21.7 \mathrm{~N}$. The surface topographies of the samples after the scratch test of Figure 6 shows that the traditional pretreated coating was shelled and cracked in the latter half of the scratch. The $10 \%$ laser energy density cleaning coating burst in the middle section, and the remaining parameters coatings did not have cracked areas. The surface of the coating with the $20 \%$ laser energy density was nearly intact. The $10 \%$ laser energy density was too small, and the cleaning was incomplete, resulting in many contaminants, with the oxide layer remaining on the substrate. During the deposition process, the coating had difficulty in adhering to the substrate, due to the presence of the contaminants and the oxide layer, resulting in less adhering strength than in the traditional method. When the laser energy density reached $20 \%$, the areas where the contaminants and oxide layer were shallower were burnt under laser radiation. Some shallow pits visible to the naked eye appeared on the surface following cleaning. The laser energy was near the substrate ablation threshold, and the cleaning effect was better. Meanwhile, the coating with a thickness of $20 \mu \mathrm{m}$ was tightly bonded to the substrate (Figure 7). 
The presence of shallow pits created a tight interlock between the coating and the substrate, further improving the adhesion of the coating and the friction of the dispersed coating [29].

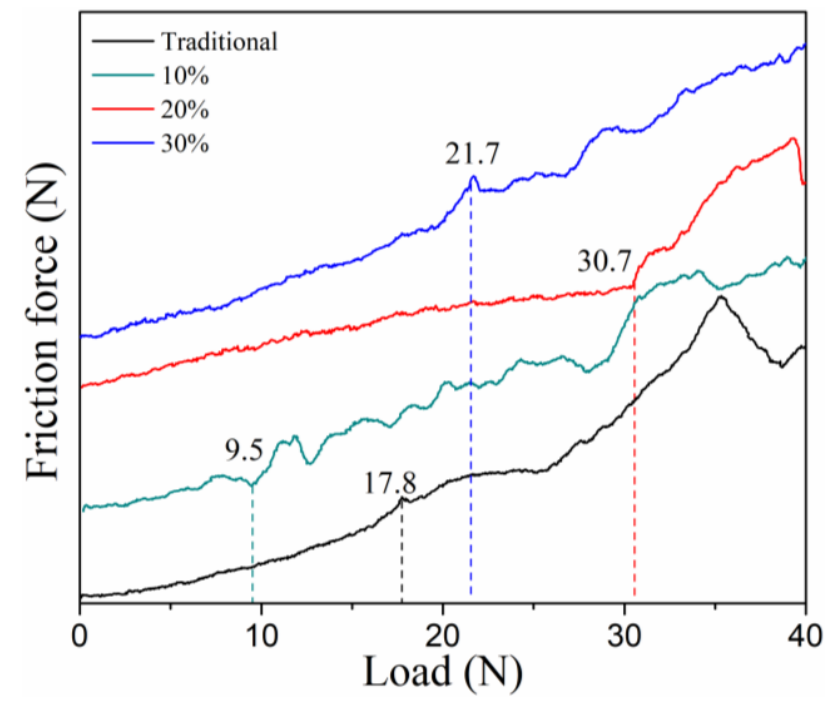

Figure 5. Traditional and laser cleaning pretreatment coatings' adhesions.

The substrate cleaned at $30 \%$ power was at a high temperature, due to the inability to dissipate heat in time. A thin yellow oxide layer was regenerated after being exposed to the air, and a large number of pits were present on the surface after cleaning. The presence of an oxide layer inevitably weakened the adhesion between the coating and the substrate. A suitable interlocking depth increased the adhesion, but extremely deep pits could reduce the wettability of the electrolyte, hinder the formation and growth of the coating at the pit, and destroy the mechanical joint [30].
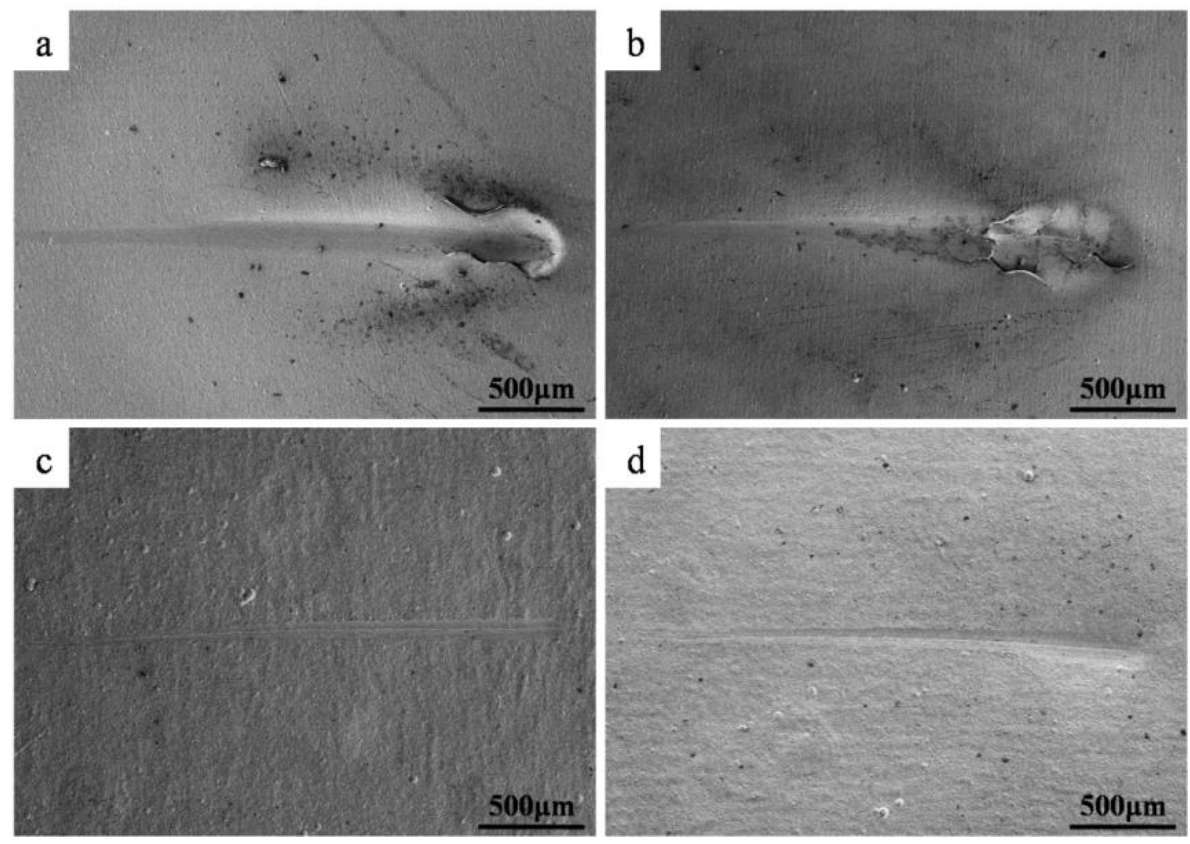

Figure 6. Morphologies of the coatings' scratch: (a) traditional pretreatment coating; (b) 10\% laser energy density cleaning coating; (c) 20\% laser energy density cleaning coating; (d) 30\% laser energy density cleaning coating. 


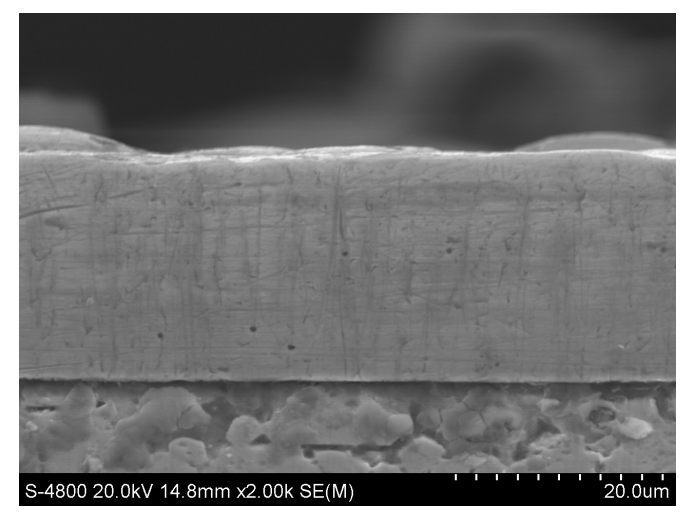

Figure 7. The cross section of the $20 \%$ laser energy density coating.

\subsection{Friction Properties and Microhardness}

The substrate and the coating were subjected to a friction test. The results showed that the friction coefficient between the titanium alloy substrate and GCr15 steel was about 0.45 at the steady state. Figure 8 a shows that the surface of the titanium alloy substrate produced a distinctly deep and dense furrow, that the wear surface was rough, and that it exhibited significant abrasive wear characteristics. Since the hardness of the titanium alloy substrate was lower than the GCr15 steel ball and lacked a hardness phase, the ability to withstand dry friction during the grinding process was weak, resulting in a large wear of the substrate [31]. The friction coefficient between the traditional pretreated coating and GCr15 steel was as high as 0.8 (Figure 8f). There were many cracks on the surface of the coating after the test, which resulted in shelling, peeling, plastic deformation, and fatigue damage (Figure 8b); the traditional pretreatment coating had large grains and weak adhesion, and the $20 \mathrm{~N}$ dry friction loads had already exceeded the adhesion, which damaged the coating [32].

The friction coefficient between the laser-cleaned coatings and GCr15 steel were generally lower than 0.8 , and the friction coefficient at $20 \%$ energy density was about 0.65 . As the time gradually increased, the remaining coatings bulged around the wear marks. This did not occur in the $20 \%$ energy density cleaning coating, proving that the adhesion of the $20 \%$ power cleaning coating was the best. Figure $8 c$,d shows the wear morphologies of the $10 \%, 20 \%$, and $30 \%$ laser energy density cleaning. At a $10 \%$ and $30 \%$ energy density, the coating produced significant cracks and some flaking. The wear marks width at the $30 \%$ energy density was uneven, which was caused by the unevenness of the coating. During the test, the protrusions first came into contact with the GCr15 steel ball to produce a high pair. As the time increased, the protrusions smoothed gradually and the grinding debris gradually accumulated with the friction pair, making a cutting motion on the coating to form wear marks, which eventually led to the cracking and peeling of the coating. At the same time, adhesion (forming a friction layer) can be found in Figure 8e, which was one reason why the friction and wear performance of the $30 \%$ laser cleaning coating was worse than at $20 \%$. However, the coating did not have as much damage and peeling as for Figure $6 b, c$, so even with adhesive wear, the wear performance of the $30 \%$ laser energy density treatment coating was better than at $10 \%$. The $20 \%$ laser energy density cleaning coating had narrow wear marks, and a few shallow scratches formed by slight scratches. There were no obvious cracks or flaking on the surface. Because the surface was relatively flat, grinding debris were pulled to the outside, and only few grinding debris moved with the friction pair to form a slight furrow. The wear mechanism of the coating was abrasive wear. 

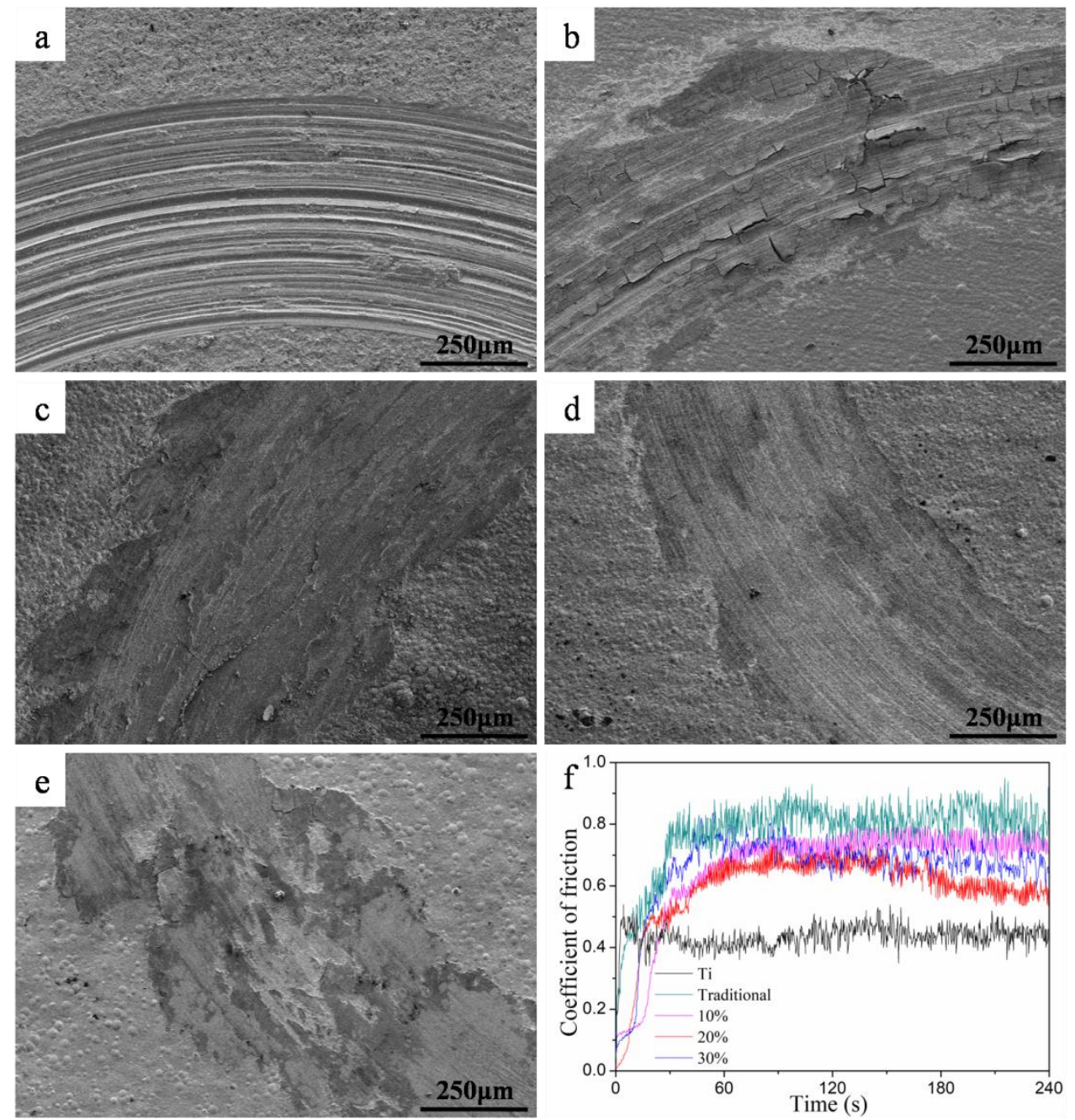

Figure 8. Morphologies of wear marks: (a) titanium alloy substrate; (b) traditional pretreatment coating; (c) 10\% laser energy density cleaning coating; (d) $20 \%$ laser energy density cleaning coating; (e) $30 \%$ laser energy density cleaning coating; (f) the coefficient friction of coatings.

In Table 3, one can see that the titanium alloy substrate had the largest wear volume for the same duration, followed by the traditional pretreatment coating, and that the lowest was the $20 \%$ laser energy density coating. Although the friction coefficient of titanium alloy was relatively low, its wear resistance was poor and wear volume was large. After nickel plating, the wear resistance was significantly improved, and the $20 \%$ laser energy density coating was the most wear-resistant.

Table 3. Substrate and coatings wear volume.

\begin{tabular}{cc}
\hline Sample & Wear Volume $/ \mathrm{mm}^{\mathbf{3}}$ \\
\hline Substrate & 1.673 \\
Traditional pretreatment & 0.113 \\
10\% laser energy density & 0.083 \\
20\% laser energy density & 0.046 \\
$30 \%$ laser energy density & 0.061 \\
\hline
\end{tabular}

It is not only the surface morphologies but also the hardness of the coatings that affects the wear resistance of the coatings. Figure 9 shows that the hardness of the titanium alloy substrate was $1362.6 \mathrm{~N} / \mathrm{mm}^{2}$, and the conventional pretreatment coating was $1799.4 \mathrm{~N} / \mathrm{mm}^{2}$. The hardness of the coatings using different laser cleaning powers initially increased and then decreased. When the 
energy density was at $20 \%$, the hardness increased from $1754.2 \mathrm{~N} / \mathrm{mm}^{2}$ to $1967.6 \mathrm{~N} / \mathrm{mm}^{2}$. When the power increased further, the hardness decreased to $1822.9 \mathrm{~N} / \mathrm{mm}^{2}$. The hardness of the coatings was positively correlated with the wear resistance. Jeong believed that under certain conditions, the hardness and the wear resistance of nickel coatings were strongly linear [33].

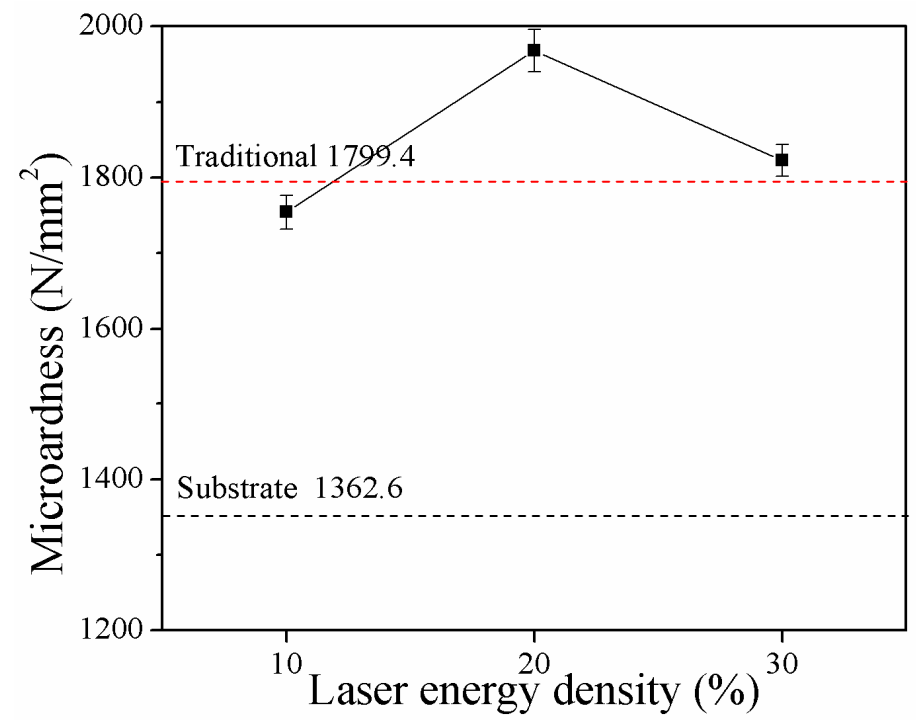

Figure 9. Hardness of the titanium alloy substrate and different pretreatment coatings.

Although the friction coefficient of the coating was higher than the substrate, it was known that the coating protected the substrate well in relation to the wear marks and the wear volume. The hardness of the coating of the $20 \%$ laser energy density cleaning was higher, as was the wear resistance.

\section{Conclusions}

In this paper, the surface mechanical properties of the SLM-formed Ti6Al4V samples were improved by a combination of the jet electrodeposition and the laser cleaning. As a novel technology, laser cleaning solves complex problems in the pre-deposition of titanium alloys, and it achieves high efficiency and environmental protection. The experimental results demonstrated that when the laser energy density reached $20 \%$, the laser energy was near the substrate ablation threshold and the cleaning effect was obvious. The contaminations and the oxide layer were removed, and some shallow pits were generated on the substrate. The presence of the shallow pits created a tight interlock between the coating and the substrate, further increasing the adhesion to $30.7 \mathrm{~N}$. Meanwhile, the coating had the crystalline grain size of $15.3 \mathrm{~nm}$, while the hardness reached $1967.6 \mathrm{~N} / \mathrm{mm}^{2}$. The friction coefficient between the coating and GCr15 steel was 0.65, and the wear volume was only $0.046 \mathrm{~mm}^{3}$. As the laser power was further increased, a yellow oxide layer appeared again on the surface of the cleaned titanium alloy, and there were many laser spots. Therefore, the wear resistance, adhesion strength and hardness of the coating weakened.

Author Contributions: Conceptualization, X.W. and Z.T.; methodology, M.X. and Z.W.; writing-original draft preparation, X.W. and M.X.; writing-review and editing, M.N.A. and C.W.; validation, L.S. and M.Q.; All authors have read and approved it.

Funding: This work was supported by the following funds: (1) Jiangsu Provincial Science and Technology Plan (Grant No. BE2017001-3); (2) National Natural Science Foundation of China (Grant No. 51475235, and No. U1537105); (3) National Key Research and Development Program of China (Grant No. 2018YFB1105400). We also extend our sincere thanks to all who contributed in the preparation of these instructions.

Conflicts of Interest: The authors declare no conflict of interest. 


\section{References}

1. Boyer, R.R. An overview on the use of titanium in the aerospace industry. Mater. Sci. Eng. A 1996, 213, 103-114. [CrossRef]

2. Zhao, Z.Y.; Li, L.; Bai, P.K.; Jin, Y.; Wu, L.Y.; Li, J.; Guan, R.G.; Qu, H.Q. The heat treatment influence on the microstructure and hardness of TC4 titanium alloy manufactured via selective laser melting. Materials 2018, 11, 1318. [CrossRef]

3. Zhu, Y.; Chen, X.; Zou, J.; Yang, H. Sliding wear of selective laser melting processed Ti6Al4V under boundary lubrication conditions. Wear 2016, 368, 485-495. [CrossRef]

4. Zhang, D.; Zhou, S.; Fan, Y.; Xu, N.; He, Y. Preparation of dense Pd composite membranes on porous Ti-Al alloy supports by electroless plating. J. Membr. Sci. 2012, 387-388, 24-29. [CrossRef]

5. Lim, Y.M.; Park, Y.J.; Yun, Y.H.; Hwang, K.S. Functionally graded Ti/HAP coatings on Ti-6Al-4V obtained by chemical solution deposition. Ceram. Int. 2002, 28, 37-41. [CrossRef]

6. Hicham, B.; Richard, D.; Joel, F.; Sylvain, P.; Thierry, G.; Hassane, O.; Dominique, L.M. Elaboration of Monophasic and Biphasic Calcium Phosphate Coatings on Ti6Al4V Substrate by Pulsed Electrodeposition Current. Adv. Eng. Mater. 2010, 12, B192-B199. [CrossRef]

7. Yang, L.; Zhang, D.; Yan, W.; Zheng, Y. Microstructure and wear properties of TiCN/Ti coatings on titanium alloy by laser cladding. Opt. Lasers Eng. 2010, 48, 119-124. [CrossRef]

8. Meng, Q.; Geng, L.; Ni, D. Laser cladding NiCoCrAlY coating on Ti-6Al-4V. Mater. Lett. 2005, 59, $2774-2777$. [CrossRef]

9. Hager, C.H., Jr.; Sanders, J.; Sharma, S.; Voevodin, A.; Segall, A. The effect of temperature on gross slip fretting wear of cold-sprayed nickel coatings on Ti6Al4V interfaces. Tribol. Int. 2009, 42, 491-502. [CrossRef]

10. Martinez, J.M.V.; Pedemonte, F.J.B.; Galvin, M.B.; Gomez, J.S.; Barcena, M.M. Sliding wear behavior of UNS R56400 titanium alloy samples thermally oxidized by laser. Materials 2017, 10, 830-843.

11. Przestacki, D.; Radomir, M.; Lidia, M.P. Experimental research of surface roughness and surface texture after laser cladding. Appl. Surf. Sci. 2016, 388, 420-423. [CrossRef]

12. Chwalczuk, T.; Przestacki, D.; Piotr, S.; Bartkowska, A. Microstructure characterization of Inconel 718 after laser assisted turning. MATEC Web Conf. 2018, 188, 02004. [CrossRef]

13. Bartkowska, A.; Aleksandra, P.; Mikolaj, P.; Dariusz, B.; Przestacki, D.; Andrzej, M. Effect of laser modification of B-Ni complex layer on wear resistance and microhardness. Opt. Laser Technol. 2015, 72, 116-124. [CrossRef]

14. Przestacki, D.; Mateusz, K.; Bartkowska, A. Influence of laser heat treatment on microstructure and properties of surface layer of Waspaloy aimed for laser-assisted machining. Int. J. Adv. Manuf. Technol. 2017, 93, 3111-3123. [CrossRef]

15. Mateusz, K.; Bartkowska, A.; Przestacki, D. Microstructure and selected properties of Monel 400 alloy after laser heat treatment and laser boriding using diode laser. Int. J. Adv. Manuf. Technol. 2018, 98, 3005-3017. [CrossRef]

16. Liu, Q.; Chen, D.; Kang, Z. One-step electrodeposition process to fabricate corrosion-resistant superhydrophobic surface on magnesium alloy. ACS Appl. Mat. Interfaces 2015, 7, 1859-1867. [CrossRef] [PubMed]

17. Zhao, K.; Shen, L.; Qiu, M.; Tian, Z.; Jiang, W. Preparation and Properties of Nanocomposite Coatings by Pulsed Current-Jet Electrodeposition. Int. J. Electrochem. Sci. 2017, 12, 8578-8590. [CrossRef]

18. Shen, L.; Wang, C.; Tian, Z.; Jiang, W.; Zhuo, W.; Zhao, K. Study on the Properties of Jet Electrodeposited Nickel Coating by Rotating Interlacing Method. Int. J. Electrochem. Sci. 2018, 13, 1831-1843. [CrossRef]

19. Jiang, W.; Shen, L.; Qiu, M.; Wang, X.; Fan, M.; Tian, Z. Preparation of Ni-SiC composite coatings by magnetic field-enhanced jet electrodeposition. J. Alloys Compd. 2018, 762, 115-124. [CrossRef]

20. Wang, C.; Shen, L.; Qiu, M.; Tian, Z.; Jiang, W. Characterizations of Ni-CeO 2, nanocomposite coating by interlaced jet electrodeposition. J. Alloys Compd. 2017, 727, 269-277. [CrossRef]

21. Ma, C.; Yu, W.; Jiang, M.; Cui, W.; Xia, F. Jet pulse electrodeposition and characterization of Ni-AlN nanocoatings in presence of ultrasound. Ceram. Int. 2018, 44, 5163-5170. [CrossRef]

22. Lin, C.; Zhao, L. Electroless Ni-P Wear-Resistant Coating on TC4 Titanium Alloy. Rare Metal. Mat. Eng. 2013, 42, 507-512. [CrossRef] 
23. Tang, J.; Azumi, K. Effect of copper pretreatment on the zincate process and subsequent electroplating of a protective copper/nickel deposit on the AZ91D magnesium alloy. Electrochim. Acta 2011, 56, 8776-8782. [CrossRef]

24. Lu, Y.F.; Song, W.D.; Low, T.S. Laser cleaning of micro-particles from a solid surface-Theory and applications. Mater. Chem. Phys. 1998, 54, 181-185. [CrossRef]

25. Tam, A.C.; Park, H.K.; Grigoropoulos, C.P. Laser cleaning of surface contaminants. Appl. Surf. Sci. 1998, 127-129, 721-725. [CrossRef]

26. Lei, Z.; Tian, Z.; Chen, Y. Summary and Prospect of Research Status of Laser Cleaning in Industrial Field. Las. Optoelect. Prog. 2018, 55, 030005. [CrossRef]

27. Yue, L.; Wang, Z.; Li, L. Material morphological characteristics in laser ablation of alpha case from titanium alloy. Appl. Surf. Sci. 2012, 158, 8065-8071. [CrossRef]

28. Wang, Y.; Shen, L.; Jiang, W.; Wang, X.; Fan, M.; Tian, Z.; Han, X. Laser processing as an alternative electrodeposition pretreatment. Surf. Coat. Technol. 2019, 357, 957-964. [CrossRef]

29. Baburaj, E.G.; Starikov, D.; Evans, J.; Shafeev, G.A.; Bensaoula, A. Enhancement of adhesive joint strength by laser surface modification. Int. J. Adhes. Adhes. 2007, 27, 268-276. [CrossRef]

30. Basu, B.J.; Hariprakash, V.; Aruna, S.T.; Lakshmi, R.V.; Manasa, J.; Shruthi, B.S. Effect of microstructure and surface roughness on the wettability of superhydrophobic sol-gel nanocomposite coatings. J. Sol.-Gel Sci. Technol. 2010, 56, 278-286. [CrossRef]

31. Guo, H.; Sun, T.; Li, J.; Yang, H. Microstructure and properties of Ni-WC coating prepared by plasma spraying of titanium alloy. China Surf. Eng. 2013, 26, 21-28. [CrossRef]

32. Jeong, D.H.; Gonzalez, F.; Palumbo, G.; Aust, K.T.; Erb, U. The effect of grain size on the wear properties of electrodeposited nanocrystalline nickel coatings. Scr. Mater. 2001, 44, 493-499. [CrossRef]

33. Jeong, D.H.; Erb, U.; Aust, K.T.; Palumbo, G. The relationship between hardness and abrasive wear resistance of electrodeposited nanocrystalline Ni-P coatings. Scr. Mater. 2003, 48, 1067-1072. [CrossRef]

(c) 2019 by the authors. Licensee MDPI, Basel, Switzerland. This article is an open access article distributed under the terms and conditions of the Creative Commons Attribution (CC BY) license (http:/ / creativecommons.org/licenses/by/4.0/). 